\title{
ANALYSIS OF CAR WASTE HEAT RECOVERY SYSTEM UTILIZING THERMOELECTRIC GENERATOR
}

This paper presents a calculation algorithm for a thermoelectric generator fitted in the exhaust system of a combustion engine. The viability of the presented calculation method was verified on an actual combustion engine. The calculations were performed for a BMW engine, and the generator design was based on a prototype from the same manufacturer. The paper includes calculations of the thermal cycle and of the parameters of exhaust gases from the engine. Subsequent calculations cover heat transfer from exhaust gases to the thermoelectric module and the amount of electric energy obtained from a series of modules. In the last part, the focus is on the influence of engine speed on the performance of the thermoelectric generator.

\section{INTRODUCTION}

Modern cars are equipped with a number of features which enhance the comfort of both the driver and the passengers. These features include air conditioning, satellite navigation, power windows, seat heating etc., and all of them are powered by an alternator. Lighting system is part of standard equipment in every car. Headlamps are fitted with two low beam bulbs and two high beam bulbs. The low beam lamps may draw between $110 \mathrm{~W}$ and $120 \mathrm{~W}$ of electric energy. The high beam lamps may draw additional $120 \mathrm{~W}$, and fog lamps require another $110 \mathrm{~W}$ of power [1]. If the list is to include position lamps, turn signals and a radio set, the total amount of energy demand may exceed $400 \mathrm{~W}$. Although a growing number of comfort features entails increased energy consumption, a great part of this equipment has been optimized, for example by substituting traditional bulbs with LED lamps. Fig. 1 shows electricity demand in cars, based on $[2,3,4]$.

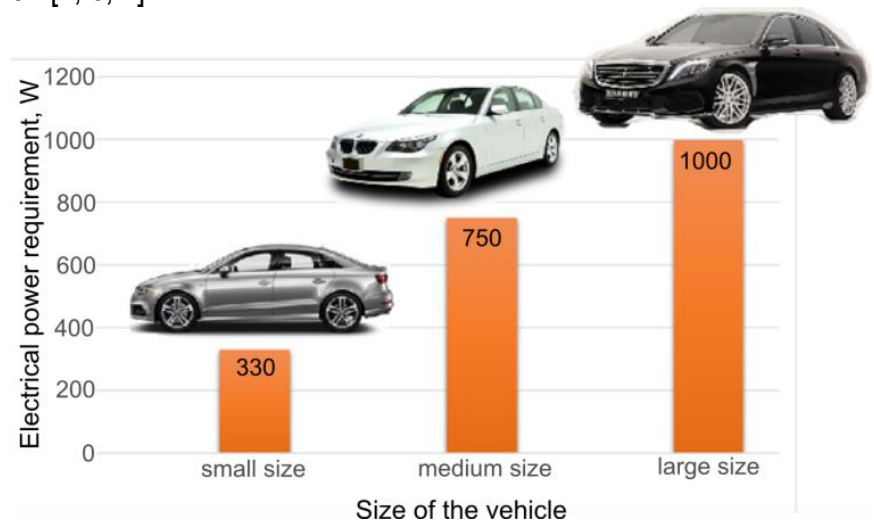

Fig. 1. Electricity demand in vehicles by size [based on 2, 3, 4]

Alternator is a device which receives mechanical power from the crankshaft. Due to its limited efficiency, the alternator consumes a significant portion of energy produced by the engine. Lowering energy consumption in vehicles has thus become the focus of much research. However, reductions in this field are possible only to some extent, as a certain level of comfort and safety must be preserved, for instance with regard to the lighting system of a vehicle. Therefore, researchers and design engineers are seeking for alternative solutions which allow limiting the use of energy taken from the crankshaft to power on-board electrical devices. The most promising solutions $[5,6]$ include Organic Rankine Cycle systems and thermoelectric generators, which are the focus of this paper.

\section{THERMOELECTRIC GENERATORS}

Thermoelectric generators may utilize waste energy from exhaust gases to limit the power output of the alternator. Their principle of operation is based on Seebeck effect, which is widely described in literature [7]. The generator is designed so as to capture thermal energy from exhaust gases and transform it into useful electrical energy.

Various generator designs represent a number of different structures and shapes. Typically, the system comprises a metal duct surrounded by thermoelectric modules and a radiator whose function is to maintain a comparatively low temperature on the cold side of the thermoelement. The cooling agent is typically a cooling liquid from the combustion engine system. Some solutions incorporate additional bypass lines which allow exhaust gases to be diverted around the TEG in the case when pressure values are excessively high in the exhaust system. The electric energy provided by the generator is managed by a controller and by a system which processes unstable voltage into nominal voltage.

As the cost of conducting research into thermoelectric generators is high, first models of such devices were used in the space, military and aviation industries.

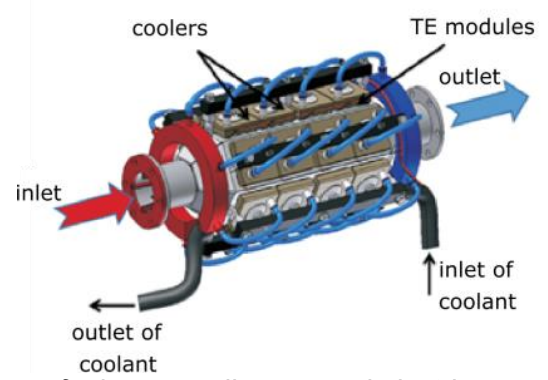

Fig. 2. A view of a hexagonally arranged electric generator [8]

One example of a hexagonal arrangement of thermoelements is provided in a generator described in [8], fitted in the exhaust system of a $1.3 \mathrm{dm}^{3}$ JTD engine. The generator has variable geometry fins. This solution is supposed to positively influence temperature distribution along the heat exchanger. 
The TEG body was made of aluminum, as this material has very high thermal conductivity and is corrosion resistant. The modules were positioned between the body and individual radiators, and were fixed with press bolts (Fig. 2). The parameters of the generator are shown in Table 1.

Tab. 1. Parameters of the generator with hexagonal geometry [8]

\begin{tabular}{|l|c|}
\hline \multicolumn{1}{|c|}{ Parameter } & Value \\
\hline Overall dimensions & $280 \mathrm{~mm} \times 555 \mathrm{~mm}$ \\
\hline Heat exchanger dimensions & $110 \mathrm{~mm} \times 311 \mathrm{~mm}$ \\
\hline Internal heat exchange surface & $0.574 \mathrm{~m}^{2}$ \\
\hline Heat exchanger material & aluminum alloy \\
\hline Number of thermoelectric modules & 24 \\
\hline Nominal power of a single TEM & $7 \mathrm{~W}\left(T_{\mathrm{C}}=50^{\circ} \mathrm{C}, T_{H}=175^{\circ} \mathrm{C}\right)$ \\
\hline $\begin{array}{l}\text { Total nominal power of the thermoelectric } \\
\text { modules }\end{array}$ & $168 \mathrm{~W}$ \\
\hline Open circuit voltage (for $\left.T_{\text {in }}=250^{\circ} \mathrm{C}\right)$ & $280 \mathrm{~V}$ \\
\hline Maximum TEM operating temperature & $200^{\circ} \mathrm{C}$ \\
\hline Total mass & $\sim 1260 \mathrm{~g}$ \\
\hline
\end{tabular}

A concept of thermoelectric generator designed at the Institute of Vehicle Concepts, German Aerospace Center (DLR) in Stuttgart was presented by the BMW Group in [2]. The model was equipped with 24 thermoelectric $\mathrm{Bi}_{2} \mathrm{Te}_{3}$ modules and with 4 cooling liquid heat exchangers, arranged in layers. a diffuser inside the exhaust gas pipe was installed in order to regulate the flow of exhaust gases. The system was implemented in a BMW 535i car with a 3.5-liter spark ignition engine. The modules are capable of withstanding maximum temperature of $250^{\circ} \mathrm{C}$ and therefore the system included an additional bypass line fitted with flap valves to ensure protection against over-heating. The cold side of the thermoelement was cooled with a coolant circulating in a separate loop. The solution is shown in Fig. 3.

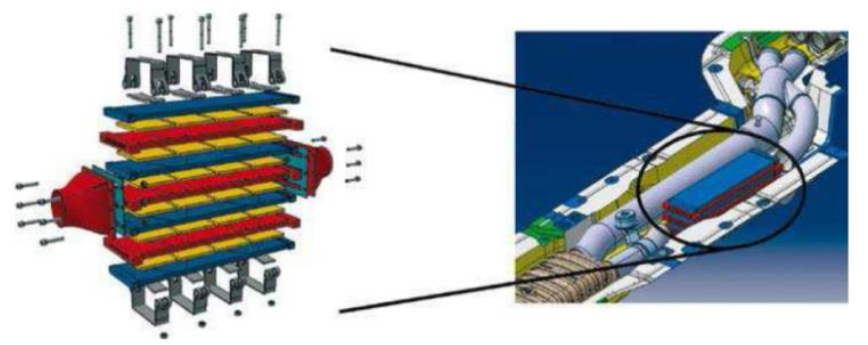

Fig. 3. Schematic diagram of the BMW-designed TEG [2]

The system was able to collect $200 \mathrm{~W}$ of electric energy at vehilce constant speed of $130 \mathrm{~km} / \mathrm{h}$. The researchers claim that in the future the power output may be significantly increased by using improved thermoelectric elements. At $250^{\circ} \mathrm{C}$, the modules used in the actual generator showed very low value of quality factor $Z T=0.4$. According to the researchers, if this value can be increased to 0.85 , the power output could reach $600 \mathrm{~W}$ [2]. More information on the current applications of thermoelectric generators can be found in [9].

Knowledge on the operating parameters of the engine and its components is vital during the design stage. This knowledge may contribute to the designing of a highly efficient system which recovers energy from waste exhaust gases and transforms it into useful energy. Although researchers and designers in large car manufacturing companies have been working on thermoelectric generators for several years, no calculation algorithm for such systems has been presented in literature so far. Moreover, many publications on this issue do not include all of the parameters which describe the process and the system of waste energy recovery. This paper aims at addressing the above issue by providing a detailed case study.

\section{THE MATHEMATICAL MODEL}

The mathematical model uses the known thermodynamic parameters of the engine's working medium, geometrical dimensions of the system's components and optimization relationships of thermoelectric modules.

The engine used in the calculations was a four stroke, six cylinder, in-line, gasoline powered BMW M50B20 model from a medium size car, whose parameters are shown in Table 2. Due to the research results obtained by the BMW Group, a decision was made to base the model on a design similar to the design described in [2].

Tab. 2. Parameters of the BMW M50B20 engine

\begin{tabular}{|l|c|c|}
\hline \multicolumn{3}{|c|}{ BMW M50 B20 } \\
\hline \multicolumn{1}{|c|}{ Parameter } & Symbol, unit & Value \\
\hline Configuration & $i$ & 6 \\
\hline Swept volume & $V_{\text {sk, }} \mathrm{dm}^{3}$ & 2 \\
\hline Power & $P_{s}, \mathrm{~kW}$ & 110 at $6000 \mathrm{rev} / \mathrm{min}$ \\
\hline Torque & $M_{0}, \mathrm{Nm}$ & 190 at $4700 \mathrm{rev} / \mathrm{min}$ \\
\hline Compression ratio & $\varepsilon$ & 10 \\
\hline Number of strokes per one work cycle & $T$ & 2 \\
\hline Fuel & - & Gasoline \\
\hline
\end{tabular}

\subsection{Stoichiometric calculations}

In order to determine the flow of exhaust gases generated by a combustion engine, air excess factor $\lambda$ should be assumed at 1.05 and fuel calorific value should be calculated. Based on literature [10], the ratio between hydrogen and carbon was assumed at $w_{h}=0.15$ and $w_{c}=0.85$, respectively. When the calorific values of those elements are known, the resultant calorific value of gasoline is calculated from (1).

$$
W_{d}=33910 \frac{\mathrm{kJ}}{\mathrm{kg}} \cdot w_{c}+121400 \frac{\mathrm{kj}}{\mathrm{kg}} \cdot w_{h}, \frac{\mathrm{kj}}{\mathrm{kg}}
$$

Table 3 shows intake fuel and air parameters used in the calculations. Under assumption that combustion is complete and perfect, combustion stoichiometry may serve to determine actual air consumption. For this purpose, the amount of oxygen per each kilogram of fuel was calculated from (2).

$$
N_{O_{2}}=\left(\frac{w_{c}}{m_{c}}+\frac{w_{h}}{w_{h}}\right), \frac{k m o l}{k g}
$$

The amount of air per each kilogram of fuel may be calculated from (3), and the actual amount of air per each kilogram of fuel is described by equation (4).

$$
\begin{aligned}
N_{\text {air }} & =\frac{N_{\mathrm{O}_{2}}}{0.21}, \frac{\mathrm{kmol}}{\mathrm{kg}} \\
N_{\text {air.act }} & =\lambda \cdot N_{\text {air }}, \frac{\mathrm{kmol}}{\mathrm{kg}}
\end{aligned}
$$

The calculation of actual air volume (5) was based on Avogadro's law.

$$
V_{\text {air.act }}=22.4 \frac{\mathrm{m}^{3}}{\mathrm{kmol}} \cdot N_{\text {air.act }}, \frac{\mathrm{m}^{3}}{\mathrm{~kg}}
$$

Tab. 3. Parameters of fuel and air at the inlet to the engine

\begin{tabular}{|c|c|c|c|c|}
\hline$W_{d}$ & $N_{02}$ & $N_{\text {air }}$ & $N_{\text {air.act }}$ & $V_{\text {air.act }}$ \\
\hline $\mathrm{kJ} / \mathrm{kg}$ & $\mathrm{kmol} / \mathrm{kg}$ & $\mathrm{kmol} / \mathrm{kg}$ & $\mathrm{kmol} / \mathrm{kg}$ & $\mathrm{m}^{3} / \mathrm{kg}$ \\
\hline 47034 & 0.108 & 0.516 & 0.542 & 12.133 \\
\hline
\end{tabular}

Further calculations were performed for several rotational speeds of the combustion engine (1500, 1750, 2000, 2250, 2500, $2750,3000,3250,3500)$. Change in the rotational speed effects a change in the amount of exhaust gases produced, which in turn affects the flux of wasted energy. The range of rotational speeds was selected so as to reflect typical operating characteristics of a combustion engine. 
Relationship (6) describes the amount of air at the inlet to the combustion chamber, while equation (7) describes the mass flow rate of the combusted fuel.

$$
\begin{aligned}
\dot{V}_{\text {air }} & =\frac{n \cdot V_{s k}}{\tau}, \frac{\mathrm{m}^{3}}{\mathrm{~s}} \\
\dot{m}_{\text {fuel }} & =\frac{\dot{V}_{\text {air }}}{V_{\text {air.act }}}, \frac{\mathrm{kg}}{\mathrm{s}}
\end{aligned}
$$

Based on literature [11], the number of kilomoles of exhaust gases per each kilogram of fuel can be expressed with relationships (8), (9), (10) and (11):

-carbon dioxide

$$
n_{\mathrm{co}_{2}}=\frac{w_{c}}{m_{c}}, \frac{\mathrm{kmol}}{\mathrm{kg}}
$$

-nitrogen

$$
n_{N_{2}}=0.79 \cdot N_{\text {air.act }}, \frac{\mathrm{kmol}}{\mathrm{kg}}
$$

-oxygen

$$
n_{\mathrm{O}_{2}}=0.21 \cdot(\lambda-1) \cdot N_{\text {air }}, \frac{\mathrm{kmol}}{\mathrm{kg}}
$$

-water

$$
m_{\mathrm{H}_{2} \mathrm{O}}=\frac{w_{c}}{w_{h}}, \frac{\mathrm{kmol}}{\mathrm{kg}}
$$

Mole flow rate of exhaust gases (12) is the product of exhaust gas components and the flow rate of combusted fuel.

$$
\dot{m}_{i}=n_{i} \cdot \dot{m}_{f u e l}, \frac{\mathrm{kmol}}{\mathrm{s}}
$$

However, mass flow rate of exhaust gases (13) is the product of the mole flow rate and the molar mass of exhaust gases.

$$
\dot{M}_{i}=\dot{m}_{i} \cdot m_{i}, \frac{\mathrm{kg}}{\mathrm{s}}
$$

Total flow rate of exhaust gases (14) is the sum of individual flow rates of exhaust gas components.

$$
\dot{M}_{e x}=\sum \dot{M}_{i}, \frac{k g}{s}
$$

In order to find mean specific heat of exhaust gases, it is necessary to calculate mass fractions of exhaust gas components (15) for each combustion product, which is the product of the component's mass flow rate and the mass of exhaust gases.

$$
g_{i}=\frac{\dot{M}_{i}}{\dot{M}_{e x}}
$$

The calculation results are presented in Table 4.

\subsection{Thermodynamic calculations}

The thermodynamic calculations were based on the ideal Otto cycle which describes the functioning of a spark ignition piston engine. The cycle consists of two adiabats (1-2,3-4) and two isochores $(2-3,4-1)$. It describes the following principle of operation: adiabatic compression of the aspirated mixture occurs from point 1 to point 2 , while isochoric combustion of fuel occurs from point 2 to point 3 . Increasing pressure causes the piston to move, thus effecting an adiabatic expansion of exhaust gases (points 3-4). They cycle ends (points 4-1) with an isochoric removal of heat. The cycle has additional charge exchange, as represented by points 1-0-1.

As the physical properties of the fuel/air mixture are slightly different than the properties of pure air, the calculations were simplified by assuming that the working medium is pure air. The assumed normal conditions were $p_{1}=1013525 \mathrm{~Pa}, T_{1}=25^{\circ} \mathrm{C}$ and the atomic mass was $\mu_{\text {air }}=0.02889 \mathrm{~g} / \mathrm{kmol}$.

Specific volume in point 1 (16) was calculated from the Clapeyron equation.

$$
v_{1}=\frac{R T_{1}}{\mu_{\text {air }} \cdot p_{1}}, \frac{\mathrm{m}^{3}}{\mathrm{~kg}}
$$

Conditions in point 2 were calculated on the basis of the compression ratio $\varepsilon$ of the BMW M50B20 engine, from (17).

$$
v_{2}=\frac{v_{1}}{\varepsilon}, \frac{\mathrm{m}^{3}}{\mathrm{~kg}}
$$

By assuming adiabatic exponent $k=1.4$, pressure and temperature in point 2 were calculated from equations (18) and (19).

$$
\begin{aligned}
& p_{2}=p_{1} \cdot \varepsilon^{\kappa}, P a \\
& T_{2}=T_{1} \cdot \varepsilon^{\kappa-1}, K
\end{aligned}
$$

Prior to calculating pressure in point 3 , it was necessary to find temperature $T_{3}$. This was done with equation (20) as described in [12].

$$
T_{3}=T_{1}+\frac{w_{d}}{\left(1+\lambda \cdot L_{t p}\right) \cdot c_{p . e x}}, K
$$

Calculating temperature from equation (20) required finding specific heat of exhaust gases. For this purpose, mean specific heat values at constant pressure were calculated (21), in accordance with [11].

$$
c_{\text {p.ex }}=\sum\left(g_{i} \cdot c_{p_{i}}\right), \frac{\mathrm{kJ}}{\mathrm{kg} \cdot \mathrm{K}}
$$

\begin{tabular}{|c|c|c|c|c|c|c|c|c|c|c|}
\hline \multirow{2}{*}{ Parameter } & \multirow{2}{*}{ Unit } & \multicolumn{9}{|c|}{ Rotational speed, rev/min } \\
\hline & & 1500 & 1750 & 2000 & 2250 & 2500 & 2750 & 3000 & 3250 & 3500 \\
\hline$\dot{V}_{\text {air }}$ & $\mathrm{m}^{3} / \mathrm{s}$ & 0.029 & 0.029 & 0.033 & 0.038 & 0.042 & 0.046 & 0.050 & 0.054 & 0.058 \\
\hline$\dot{m}_{\text {fuel }}$ & $\mathrm{kg} / \mathrm{s} \cdot 10^{-3}$ & 2.404 & 2.404 & 2.747 & 3.091 & 3.434 & 3.777 & 4.121 & 4.464 & 4.808 \\
\hline$n_{\mathrm{CO}_{2}}$ & $\mathrm{kmol} / \mathrm{kg}$ & \multicolumn{9}{|c|}{0.071} \\
\hline$n_{N_{2}}$ & $\mathrm{kmol} / \mathrm{kg}$ & \multicolumn{9}{|c|}{0.428} \\
\hline$n_{O_{2}}$ & $\mathrm{kmol} / \mathrm{kg}$ & \multicolumn{9}{|c|}{0.005} \\
\hline$n_{\mathrm{H}_{2} \mathrm{O}}$ & $\mathrm{kmol} / \mathrm{kg}$ & \multicolumn{9}{|c|}{0.075} \\
\hline$\dot{M}_{\mathrm{CO}_{2}}$ & $\mathrm{~kg} / \mathrm{s}$ & 0.007 & 0.007 & 0.008 & 0.009 & 0.011 & 0.012 & 0.013 & 0.014 & 0.015 \\
\hline$\dot{M}_{N_{2}}$ & $\mathrm{~kg} / \mathrm{s}$ & 0.029 & 0.029 & 0.033 & 0.037 & 0.041 & 0.045 & 0.049 & 0.053 & 0.058 \\
\hline$\dot{M}_{O_{2}}$ & $\mathrm{~kg} / \mathrm{s}$ & 0.001 & 0.001 & 0.001 & 0.001 & 0.001 & 0.001 & 0.001 & 0.001 & 0.001 \\
\hline$\dot{M}_{\mathrm{H}_{2} \mathrm{O}}$ & $\mathrm{kg} / \mathrm{s}$ & 0.003 & 0.003 & 0.003 & 0.004 & 0.004 & 0.005 & 0.005 & 0.006 & 0.006 \\
\hline$\dot{M}_{e x}$ & $\mathrm{~kg} / \mathrm{s}$ & 0.040 & 0.040 & 0.046 & 0.051 & 0.057 & 0.063 & 0.068 & 0.074 & 0.080 \\
\hline$g_{\mathrm{CO}_{2}}$ & - & \multicolumn{9}{|c|}{0.188} \\
\hline$g_{N_{2}}$ & - & \multicolumn{9}{|c|}{0.721} \\
\hline$g_{\mathrm{O}_{2}}$ & - & \multicolumn{9}{|c|}{0.010} \\
\hline$g_{\mathrm{H}_{2} \mathrm{O}}$ & - & \multicolumn{9}{|c|}{0.081} \\
\hline$\dot{Q}_{\text {ex }}$ & kW & 35.7 & 35.7 & 40.8 & 45.9 & 51.1 & 56.2 & 61.3 & 66.4 & 71.5 \\
\hline
\end{tabular}

Air consumption per one kilogram of combusted fuel was calculated from equation (22), described in [12].

$$
L_{t p}=\frac{1}{0.232}\left(\frac{8}{3} \cdot w_{c}+8 \cdot w_{h}\right), \frac{\mathrm{kg} \text { air }}{\mathrm{kg} \mathrm{fuel}}
$$

Subsequently, pressure in point 3 was determined using isochoric equation (23).

$$
p_{3}=\frac{p_{2} \cdot p_{3}}{T_{2}}, P a
$$

Pressure and temperature in point 4 were calculated from adiabatic equations (24) and (25). The total flux of energy lost in the exhaust gases is expressed in relationship (26).

$$
p_{4}=\frac{p_{3} \cdot v_{3}^{\kappa}}{v_{4}^{\kappa}}, P a
$$

Tab. 4. Calculated parameters for individual rotational speeds 


$$
\begin{gathered}
T_{4}=\frac{T_{3}}{\left(\frac{v_{4}}{v_{3}}\right)^{K-1}}, K \\
\dot{Q}_{e x}=\dot{M}_{e x} \cdot c_{p . e x} \cdot\left(T_{4}-T_{1}\right), W
\end{gathered}
$$

Tab. 5. Parameters in the characteristic points of the Otto cycle

\begin{tabular}{|c|c|c|c|c|c|}
\hline \multirow{2}{*}{ Parameter } & \multirow{2}{*}{ Unit } & \multicolumn{4}{|c|}{ Point } \\
\cline { 3 - 6 } & & 1 & 2 & 3 & 4 \\
\hline$p$ & $\mathrm{MPa}$ & 0.101 & 2.545 & 8.567 & 0.341 \\
\hline$v$ & $\mathrm{~m}^{3} / \mathrm{kg}$ & 0.847 & 0.085 & 0.085 & 0.847 \\
\hline$T$ & $\mathrm{~K}$ & 298.2 & 748.9 & 2520.7 & 1004.5 \\
\hline
\end{tabular}

Table 5 shows the parameters of the working medium used in the combustion engine. The temperature calculated in point 4 is the temperature of exhaust gases escaping through the exhaust system. Its value of approximately $730^{\circ} \mathrm{C}$ is consistent with the values proposed in literature $[10,11,12]$. Table 6 shows specific heat values of exhaust gases and mean specific heat values of exhaust gas components for the 298-3500 K temperature range. The flux of heat lost with the exhaust gases for various rotational speeds is provided in Table 4.

Tab. 6. Specific heat values of exhaust gases and mean specific heat values of exhaust gas components for the temperature range

\begin{tabular}{|c|c|c|c|c|c|}
\hline \multirow{2}{*}{ Parameter } & \multirow{2}{*}{ Unit } & \multicolumn{4}{|c|}{ Exhaust gas component } \\
\cline { 3 - 6 } & $\mathrm{CO}_{2}$ & $\mathrm{O}_{2}$ & $\mathrm{H}_{2} \mathrm{O}$ & $\mathrm{N}_{2}$ \\
\hline$C_{p}$ & $\mathrm{~kJ} / \mathrm{kg} \cdot \mathrm{K}$ & 1.051 & 1.095 & 2.518 & 1.187 \\
\hline$C_{\rho}$ e. & $\mathrm{kJ} / \mathrm{kg} \cdot \mathrm{K}$ & \multicolumn{4}{|c}{1.268} \\
\hline
\end{tabular}

\section{Heat exchange between the exhaust gases and the thermoelec-} tric generator

The calculations were based on the 2411G-7L31-15CX1 thermoelectric module manufactured by Customthermoelectric and shown in Fig. 4.

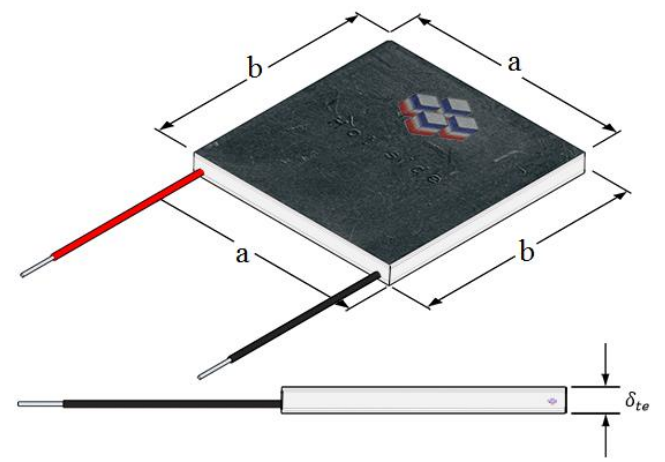

Fig. 4. Overall dimensions of the thermoelectric module [13]

The module is made of a PbTe compound, and its parameters and overall dimensions are presented in Table 8.

Tab. 8. Parameters of the Customthermoelectric 2411G-7L31-

\begin{tabular}{|c|c|c|}
\hline Parameter & Unit & Value \\
\hline$a$ & $\mathrm{~m}$ & 0.056 \\
\hline$b$ & $\mathrm{~m}$ & 0.056 \\
\hline$A_{t e}$ & $\mathrm{~m}^{2}$ & $3.136 \cdot 10^{-3}$ \\
\hline$\delta_{t e}$ & $\mathrm{~m}$ & 0.005 \\
\hline$\lambda_{t e}$ & $\mathrm{~W} / \mathrm{m} \cdot \mathrm{K}$ & 2.18 \\
\hline$T_{\text {max.te }}$ & $\mathrm{K}$ & 593.15 \\
\hline
\end{tabular}
$15 C X 1$ module [13]

In order to determine the amount of heat absorbed by the thermoelement, volumetric exhaust gas flow was calculated from equation (27), and exhaust gas density was determined by transforming the Clapeyron equation (28).

$$
\begin{aligned}
& \dot{V}_{e x}=\frac{\dot{M}_{e x}}{\rho_{e x}}, \frac{\mathrm{m}^{3}}{\mathrm{~s}} \\
& \rho_{e x}=\frac{p_{4}}{R_{Z} T_{4}}, \frac{\mathrm{kg}}{\mathrm{m}^{3}}
\end{aligned}
$$

Equivalent gaseous constant was calculated from (29).

$$
R_{Z}=8.3144 \cdot \sum \frac{g_{i}}{m_{i}}, \frac{J}{\mathrm{~kg} \cdot \mathrm{K}}
$$

The overall dimensions required to perform initial calculations were determined by the thermoelectric module. It was assumed that the generator will consist of the hot layer, cold layer and thermoelectric layer. The hot layer will consist of channels accommodating exhaust gases; the cold layer - of channels accommodating the coolant; the thermoelectric layer will comprise thermoelectric cells. Based on literature $[2,14,15]$, it was assumed that the cold side of the thermoelement can be kept at temperature $T_{C}=50^{\circ} \mathrm{C}$. The number of generator rows was due to the amount of electric energy collected by the modules and to the value of the counterpressure. Exhaust gases were assumed to flow through three channels, each having height $u$ $=5 \mathrm{~mm}$. Each row was decided to accommodate 6 thermoelements (Fig. 5)

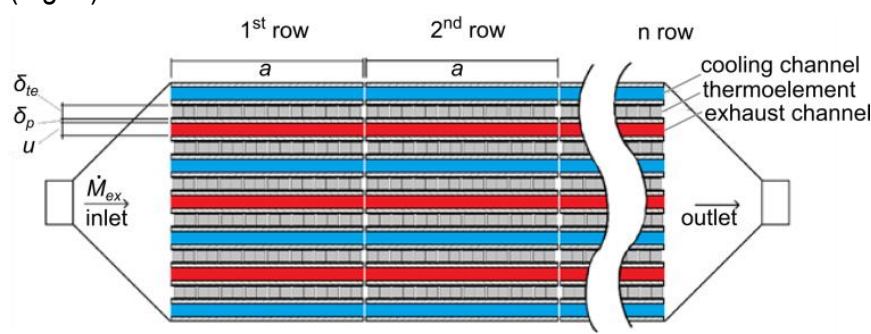

Fig. 5. Schematic diagram of the thermoelectric generator

Exhaust gas velocity in each channel was calculated from (30).

$$
w_{e x}=\frac{\dot{V}_{e x}}{3 \cdot(a \cdot u)}, \frac{m}{s}
$$

Equivalent hydraulic diameter was calculated on the basis of equation (31).

$$
d_{h}=4 \cdot \frac{A_{k}}{o_{k}}, m
$$

Heat conductivity coefficient was based on the temperature of the medium and on literature [16] and calculated from relationships (32), (33), (34) and (35).

$$
\begin{gathered}
\lambda_{\mathrm{CO}_{2}}=1.41 \cdot 10^{-2}+7.6444 \cdot 10^{-5} \mathrm{~T}_{4}+ \\
3.7778 \cdot 10^{-8} T_{4}^{2}-8.8889 \cdot 10^{-11} T_{4}^{3}, \frac{\mathrm{W}}{\mathrm{m} \cdot \mathrm{K}} \\
\lambda_{\mathrm{H}_{2} \mathrm{O}}=1.7 \cdot 10^{-2}+5.6983 \cdot 10^{-5} \mathrm{~T}_{4}+ \\
1.297172 \cdot 10^{-7} \mathrm{~T}_{4}^{2}-9.13131 \cdot 10^{-11} \mathrm{~T}_{4}^{3}, \frac{\mathrm{W}}{\mathrm{m} \cdot \mathrm{K}} \\
\lambda_{\mathrm{O}_{2}}=2.38 \cdot 10^{-2}+9.4414 \cdot 10^{-5} \mathrm{~T}_{4}+ \\
-1.352525 \cdot 10^{-7} \mathrm{~T}_{4}^{2}-1.8989 \cdot 10^{-10} \mathrm{~T}_{4}^{3}, \frac{\mathrm{W}}{\mathrm{m} \cdot \mathrm{K}} \\
\lambda_{\mathrm{N}_{2}}=2.43 \cdot 10^{-2}+7.4717 \cdot 10^{-5} \mathrm{~T}_{4}+ \\
-7.1616 \cdot 10^{-8} \mathrm{~T}_{4}^{2}+6.8686 \cdot 10^{-11} \mathrm{~T}_{4}^{3}, \frac{\mathrm{W}}{\mathrm{m} \cdot \mathrm{K}}
\end{gathered}
$$

Mean heat conductivity coefficient was determined from equation (36).

$$
\lambda_{\text {ex }}=\sum g_{i} \cdot \lambda_{i}, \frac{w}{m \cdot K}
$$

Using data provided in [16] as well as equations (37), (38), (39) and (40), dynamic viscosity coefficients were determined for exhaust gas components, in a manner analogous to the heat conductivity coefficients.

$$
\begin{gathered}
\eta_{\mathrm{CO}_{2}}=1.37 \cdot 10^{-5}+4.7033 \cdot 10^{-8} \mathrm{~T}_{4}{ }^{+} \\
-2.5666 \cdot 10^{-11} \mathrm{~T}_{4}^{2}+1.3333 \cdot 10^{-14} \mathrm{~T}_{4}^{3}, \mathrm{~Pa} \cdot \mathrm{s} \\
\eta_{\mathrm{H}_{2} \mathrm{O}}=9.60 \cdot 10^{-6}+2.7813 \cdot 10^{-8} \mathrm{~T}_{4}+ \\
4.6269 \cdot 10^{-11} \mathrm{~T}_{4}^{2}-5.0545 \cdot 10^{-14} \mathrm{~T}_{4}^{3}, \mathrm{~Pa} \cdot \mathrm{s} \\
\eta_{\mathrm{O}_{2}}=1.88 \cdot 10^{-5}+6.0260 \cdot 10^{-8} T_{4}{ }^{+} \\
-6.1272 \cdot 10^{-11} T_{4}^{2}+5.5757 \cdot 10^{-14} T_{4}^{3}, \mathrm{~Pa} \cdot \mathrm{s}
\end{gathered}
$$

\section{AUTOBUSY 6/2018}


$\eta_{N_{2}}=1.67 \cdot 10^{-5}+4.3805 \cdot 10^{-8} T_{4}+$

$-2.0494 \cdot 10^{-11} T_{4}^{2}+6.8686 \cdot 10^{-15} T_{4}^{3}, \mathrm{~Pa} \cdot \mathrm{s}$

Mean kinematic viscosity was calculated from (41).

$$
v_{e x}=\frac{\sum g_{i} \cdot \eta_{i}}{\rho_{e x}}, \frac{m^{2}}{s}
$$

Reynolds number for exhaust gases flowing through the channel was found on the basis of (42).

$$
R e_{e x}=\frac{w_{e x} \cdot \lambda_{e x}}{d_{h}}
$$

The flow was turbulent for each rotational speed, and therefore, as suggested in literature [17], the Nusselt number was calculated from equation (43), and exhaust gas heat transfer coefficient was calculated from (44).

$$
\begin{gathered}
N u_{e x}=0.021 R e_{e x}^{0.8} \cdot P r_{e x}^{0.43} \\
h_{e x}=\frac{N u_{e x} \cdot \lambda_{e x}}{d_{h}}, \frac{W}{m^{2} K}
\end{gathered}
$$

In order to perform further calculations, it was assumed that the structural components of the generator are made of stainless steel St $44 \mathrm{~K}(\mathrm{P} 355 \mathrm{GH})$, which displays significant resistance to high temperatures. The assumed wall thickness was $\delta_{p}=0.002 \mathrm{~m}$. The material has heat conductivity coefficient $\lambda_{p}=50 \mathrm{~W} /(\mathrm{m} \cdot \mathrm{K})$. Fig. 6 shows the distribution of temperatures and heat fluxes.

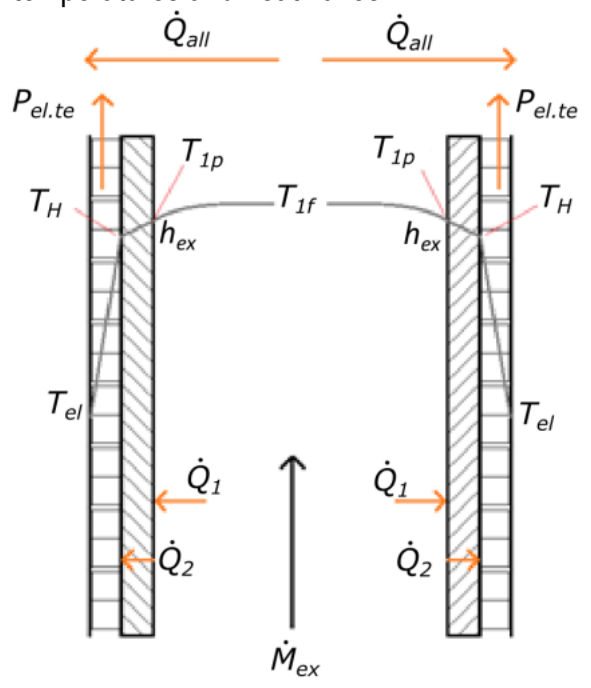

Fig. 6. Distribution of temperatures and heat fluxes for a fragment of the exhaust gas channel surrounded with thermoelements

The calculations were primarily aimed at finding temperature $T_{H}$ on the hot side of the thermoelement, so as to determine the amount of electric energy generated by the module. Prior calculations, however, should provide the total flux of heat transferred from the exhaust gases through the wall to the thermoelement. Heat exchange takes place through forced convection. $T_{1 f}$ is the temperature of exhaust gases, $T_{1 p}$ is the temperature of the wall, $T_{H}$ is the unknown temperature on the hot side of the module, $T_{C}$ is the temperature on the cold side of the module, as based on literature $[2,14,15]$.

Total heat flux was calculated on the basis of the Fourier law and Newton's law, and is expressed with relationship (45).

$$
\dot{Q}_{a l l}=\frac{T_{1 f}-T_{C}}{\frac{1}{h_{e x}}+\frac{\delta_{p}}{\lambda_{p}}+\frac{\delta_{t e}}{\lambda_{t e}}} \cdot A_{t e}, W
$$

According to the heat transfer law, the fluxes in each of the walls are equal, and thus equation (46) is valid.

$$
\dot{Q}_{1}=\dot{Q}_{2}=\dot{Q}_{\text {all }}
$$

Based on this relationship, the temperature of the wall and of the exhaust gas channel was calculated from (47).

$$
T_{1 p}=T_{1 f}-\frac{\dot{Q}_{1}}{h_{e x} A_{t e}}, K
$$

Observing the $T_{H}<T_{\text {max.te }}$ condition, temperature on the hot side of the thermoelement was calculated from equation (48).

$$
T_{H}=T_{1 p}-\frac{\dot{Q}_{2} \cdot \delta_{p}}{\lambda_{p} \cdot A_{t e}}, K
$$

Using the power characteristic of the thermoelement as a function of the temperature on the cold side and on the hot side of the thermoelement (Fig. 7), relationship (49) was established, which allows finding the generated electric power.

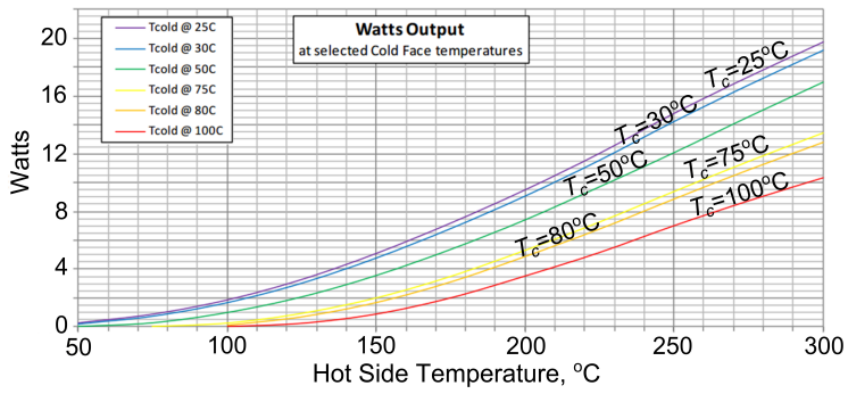

Fig. 7. Power characteristic of the thermoelement as a function of the cold and hot temperature [13]

$$
\begin{gathered}
P_{\text {el.te }}=6.526 \cdot 10^{-14} T_{H}^{6}-1.777 \cdot 10^{-10} T_{H}^{5}+ \\
1.992 \cdot 10^{-7} T_{H}^{4}-0.001 T_{H}^{3}+0.038 T_{H}^{2}+ \\
-6.894 T_{H}+509.137, W
\end{gathered}
$$

Relationship (50) describes heat flux transferred from exhaust gases in each of the three channels of the nth row.

$$
\begin{aligned}
& \dot{Q}_{\text {ex.n1.3 }}=\dot{Q}_{\text {ex. } 2.3}=\dot{Q}_{\text {ex.3.3 }}= \\
& =\frac{\dot{M}_{\text {ex }}}{3} \cdot c_{p . e x} \cdot\left(T_{1 f}-T_{a m b}\right), W
\end{aligned}
$$

Considering the fact that exhaust gas heat flux is absorbed by the upper and by the lower wall of the channel, heat flux in the subsequent row was calculated from (51).

$$
\dot{Q}_{\text {ex. }(n+1) 1.3}=\dot{Q}_{\text {ex. } n 1.3}-2 \cdot \dot{Q}_{1}, W
$$

Thus, exhaust gas temperature in the $n+1$ row was calculated from relationship (52)

$$
T_{1 f n+1}=\frac{\dot{Q}_{\text {ex.n1.3 }}-2 \dot{Q}_{1}}{\frac{\dot{M}_{\text {ex }}}{3} c_{p . e x}}, K
$$

The temperature decrease between the nth row and the $n+1$ row is expressed with equation (53).

$$
\Delta T_{n}=T_{1 f n}-T_{1 f n+1}, K
$$

The total electric energy produced in one row is a sum from all modules in that row and is expressed with (54).

$$
P_{e l}=6 \cdot P_{\text {el.te }}, W
$$

\section{Pressure losses}

The number of rows in the generator was determined on the basis of the loss of pressure generated by the TEG. Literature studies indicate $[2,18]$ that the projects generated pressure losses of $30-65$ millibars, and thus 65 mbar was assumed to be the upper limit determining the number of thermoelement rows. Pressure drop was calculated on the basis of [19]. For this purpose, equation (55) was used to determine equivalent diameter (Fig. 8) for the three channels.

$$
d_{h 3}=\sqrt{3} \cdot d_{h}
$$

The assumed exhaust pipe diameter being $d_{i n}=0.047 \mathrm{~m}$, relationship (56) served to calculate exhaust gas speed.

$$
w_{e d}=\frac{\dot{V}_{e x}}{\frac{\pi d_{w}^{2}}{4}}, \frac{m}{s}
$$




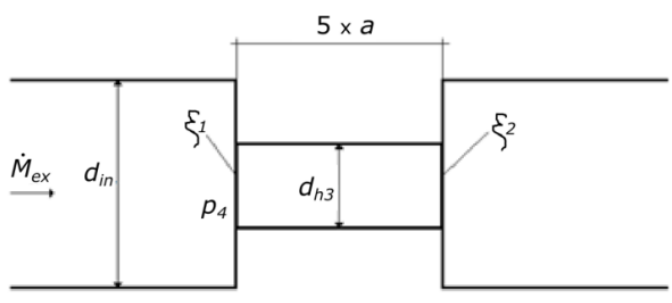

Fig. 8. An illustration of the narrowing formed by the TEG

Based on the data provided in [19], both local loss coefficient and linear loss coefficient were determined. Local loss coefficient on the inlet was calculated from (57). The coefficient on the outlet was assumed to be $\xi_{2}=1$, and linear loss coefficient was assumed to be $\lambda_{s \mid}=0.03$.

$$
\xi_{1}=0.5 \cdot\left(1-\left(\frac{d_{h 3}}{d_{\text {in }}}\right)^{2}\right)=0.443
$$

Both local and linear losses were calculated on the basis of [19], from relationships (58) and (59).

$$
\begin{gathered}
\Delta h_{m}=\xi \cdot \frac{w_{e d}^{2}}{2 \cdot g}, m \\
\Delta h_{l}=\lambda_{s l} \cdot \frac{5 \cdot a}{d_{h 3}} \cdot \frac{w_{e x}^{2}}{2 \cdot g}, m
\end{gathered}
$$

Total pressure loss $(60)$ is the sum of individual losses.

$$
\Delta h=\Sigma \Delta h_{m}+\Sigma \Delta h_{l}, m
$$

Pressure drop is described with equation (61).

$$
\Delta p=\rho_{e x} \cdot g \cdot \Delta h, P a
$$

\section{ANALYSIS OF THE RESULTS}

After all of the calculations had been performed, it was decided that the generator would consist of 5 thermoelement rows, 6 modules each. This number was due to the 63 mbar counterpressure, which was observed at $3500 \mathrm{rev} / \mathrm{min}$. Hence, the total number of $30 \mathrm{mod}-$ ules provide $450 \mathrm{~W}$ of electric energy at the rotational speed of $2000 \mathrm{rev} / \mathrm{min}$. Based on an assumption that the engine is installed in a medium-size car whose electric energy consumption is approximately $750 \mathrm{~W}$, the modules provide $60 \%$ of the required energy. Additional parameters are shown in Fig. 9.

The maximum allowable temperature on the hot side of the thermoelectric module is $593 \mathrm{~K}$. The black line in Fig. 9 represents the limit, above which the $T_{H 1}$ temperatures on the hot side of the module (in the first row) exceed the $T_{\text {max.te }}$ temperature. The authors decided not to modify the calculations performed for higher rotational speeds for two reasons. The first reason is that producing much electric energy already in the lowest rotational speeds of the combustion engine is an advantageous solution. The second reason is to demonstrate the gains expected from a thermoelectric generator. Thermoelectric materials are being continuously developed and modules having higher efficiency and operating temperatures above $320^{\circ} \mathrm{C}(593 \mathrm{~K})$ will become commercially available in the future.

One of the methods to prevent a thermoelectric generator from overheating is to employ a special bypass. In the case when the mass flow of exhaust gases is excessive, such a device would allow the gases to be diverted around the generator and sent directly to the atmosphere, simultaneously maintaining the temperature on the hot side of the module within limits. Solutions of this type are offered by a number of companies which are engaged in research on thermoelectric generators applied in vehicles.

The $\eta_{T E G}$ efficiency, i.e. the ratio between heat transferred through the walls and electric energy produced by the modules, was approximately $24-26 \%$. However, if the generated electric power is viewed in relation to the energy of the exhaust gases, the total efficiency did not exceed $1.1 \%$. This limitation is dictated by the still insufficient amount of heat transferred from the exhaust gases to the walls.

Fig. 10 shows the values of volumetric exhaust gas flow and the pressure drop generated by the system. All of the values are consistent with the tolerance limits suggested in literature $[2,18]$. It is worth mentioning that with a bypass applied, the drops would be significantly limited above $2000 \mathrm{rev} / \mathrm{min}$.

Fig. 11 is a visual representation of the analyzed generator, while Fig. 12 shows its layers.

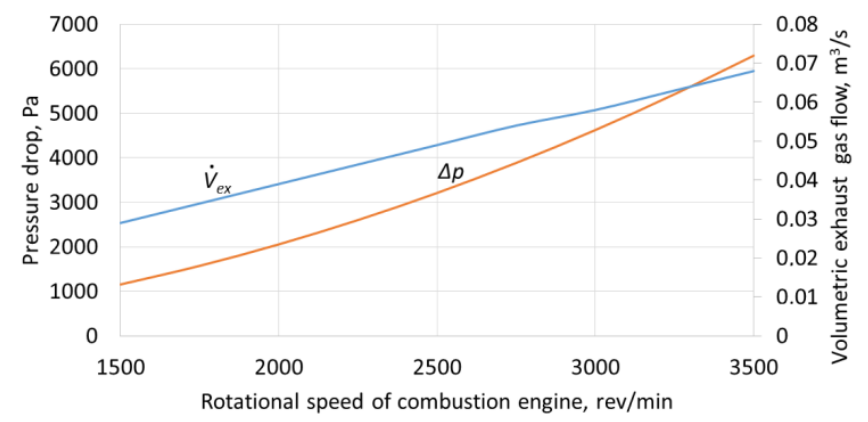

Fig. 10. Volumetric exhaust gas flow and the pressure drop

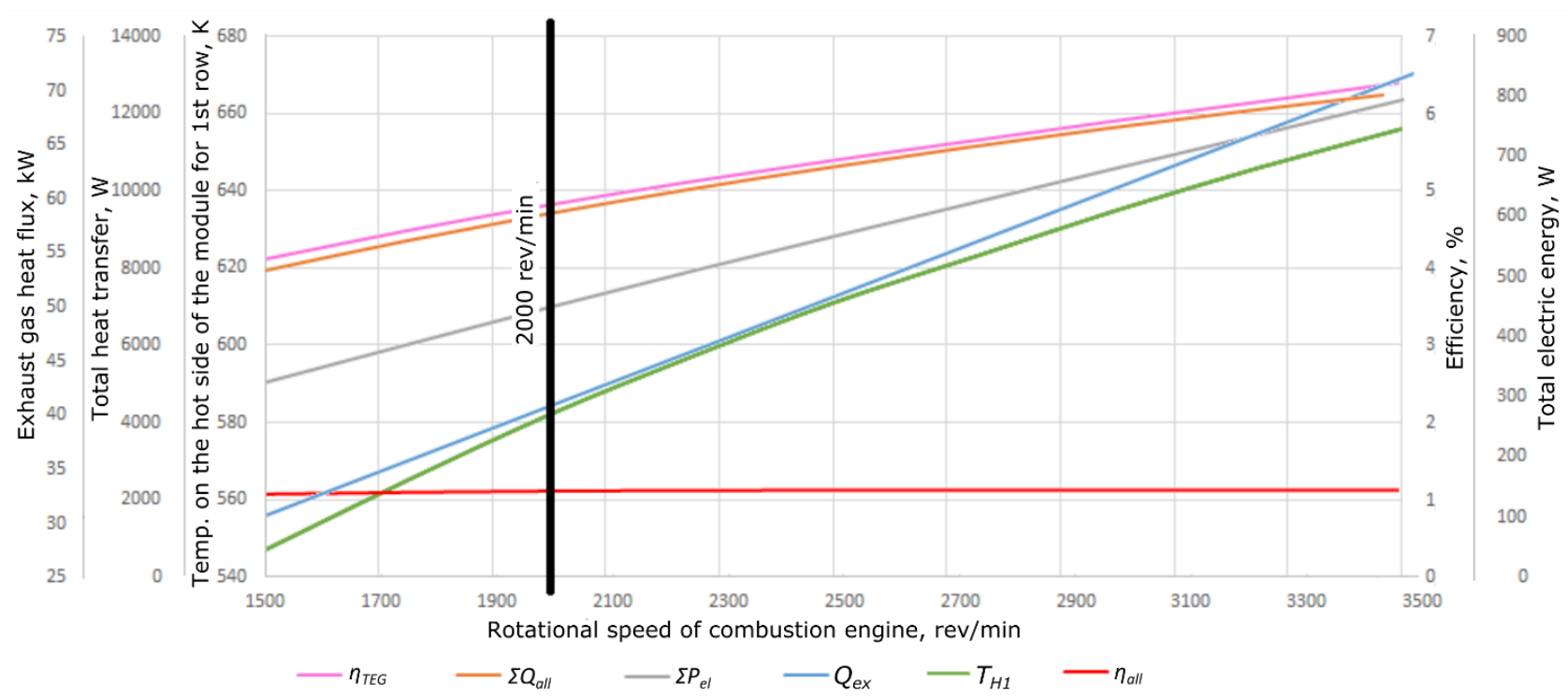

Fig. 9. Resultant characteristics of the thermoelectric generator 


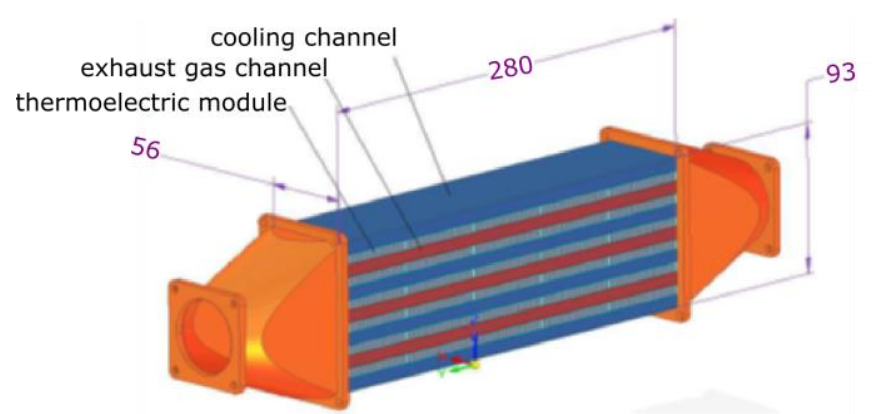

Fig. 11. Thermoelectric generator - assembled

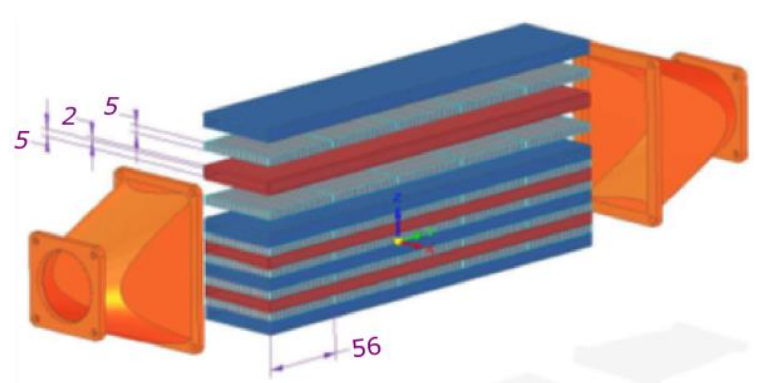

Fig. 12. Thermoelectric generator - disassembled

\section{SUMMARY AND CONCLUSIONS}

This paper presents a calculation algorithm for analyzing the application of a thermoelectric generator to the process of recovering waste heat from a combustion engine and converting it to useful energy. Additionally, by performing the calculations on a particular example, it was possible to determine the process and geometric parameters of the module, as these parameters are not offered in the relevant literature. The study was based on the model of a BMW M50B20 spark ignition engine and started with stoichiometric calculations. The results allowed to find mass flow rate of exhaust gases, which is between $0.034 \mathrm{~kg} / \mathrm{s}$ and $0.080 \mathrm{~kg} / \mathrm{s}$ within the range of $1500 \div 3500 \mathrm{rev} / \mathrm{min}$. The increase of the flow rate was accompanied by an increase of heat flux lost to the atmosphere - between $30 \mathrm{~kW}$ and $70 \mathrm{~kW}$. In the case of an engine having nominal power equal to $110 \mathrm{~kW}$, losses in the exhaust system ranged from $27 \%$ to $63 \%$. In the next step, the temperature in the exhaust system was determined, and its value proved consistent with the values offered in literature, i.e. approximately $730^{\circ} \mathrm{C}$. This information served to calculate heat exchange. The thermoelectric module was selected from among the best commercially available devices. Its maximum operating temperature was $320^{\circ} \mathrm{C}$. Based on the characteristics disclosed in the product data sheet, a relationship was deduced which allowed calculating the generated electric energy as a function of temperature on the hot and on the cold side of the module. The cold side temperature of the module was here assumed at $50^{\circ} \mathrm{C}$. This value was dictated by the properties of the analyzed materials, in which this temperature level was possible to maintain. The assumed generator had a layer structure. Data offered in literature served to establish allowable pressure drop which can be generated by a system of this type, and the length of the exhaust gas channels in the generator was decided to correspond to five lengths of the selected thermoelectric module. Within the $1500 \div 2000$ rotational speed range, the generator was capable of delivering between $325 \mathrm{~W}$ and $450 \mathrm{~W}$ of power. These values correspond respectively to $43 \%$ and $60 \%$ of the total electric energy demand in a car. The efficiency of the generator, in relation to the total energy lost in exhaust gases, was approximately $1 \%$. Above 2000 $\mathrm{rev} / \mathrm{min}$, temperatures on the hot side of the thermoelement ex- ceeded the maximum allowable value. In order to prevent the generator from overheating, further research may focus on designing a bypass for exhaust gases to be diverted around the generator. Future works may also be aimed at designing a cooling system for the complete generator, which will additionally enable more precise measurement of the generated energy.

\section{NOMENCLATURE}

$A_{t e}$ - surface of the thermoelectric module, $\mathrm{m}^{2}$

$c_{p}$ - specific heat, $\mathrm{kJ} / \mathrm{kg} \cdot \mathrm{K}$

$d_{h}$ - equivalent diameter, $\mathrm{m}$

$d_{\text {in }}$ - inner diameter, $\mathrm{m}$

$e$ - electric charge, $\mathrm{C}$

$E$ - kinetic energy, J

$E_{F A, F B}-$ Fermi energy, eV

$g$ - mass fractions of exhaust gas components

$i$ - ratio of the number of cylinders in an in-line combustion engine

$L_{t p}$ - air consumption, $\mathrm{kg} / \mathrm{kg}$

$m$ - flywheel mass, $\mathrm{kg}$

$\dot{m}$ - mole flow rate of exhaust gas components, kmol/s

$\dot{m}_{\text {fuel }}$ - mass flow rate of fuel, $\mathrm{kg} / \mathrm{s}$

$M_{o}$ - torque, $\mathrm{Nm}$

$\dot{M}$ - mass flow rate of exhaust gas components, $\mathrm{kg} / \mathrm{s}$

$\dot{M}_{e x}$ - total mass flow rate of exhaust gases, $\mathrm{kg} / \mathrm{s}$

$n_{c o 2}$ - amount of $\mathrm{CO}_{2}$ produced from fuel, $\mathrm{kmol} / \mathrm{kg}$

$n_{O 2}$ - amount of $\mathrm{O}_{2}$ produced from fuel, $\mathrm{kmol} / \mathrm{kg}$

$n_{\mathrm{H} 2 \mathrm{O}}$ - amount of $\mathrm{H}_{2} \mathrm{O}$ produced from fuel, $\mathrm{kmol} / \mathrm{kg}$

$n_{N 2}-$ amount of $\mathrm{N}_{2}$ produced from fuel, $\mathrm{kmol} / \mathrm{kg}$

$n$ - rotational speed of combustion engine, rev/min

$N$ - oxidizer to fuel ratio, $\mathrm{kmol} / \mathrm{kg}$

$\mathrm{Nu}$ - Nusselt number

$p$ - pressure, $\mathrm{Pa}$

$P_{e l}$ - total electric energy produced by 1 row of thermoelements, W

$P_{e l . t e}$ - electric power of the thermoelectric module, $\mathrm{W}$

$P_{\mathrm{s}}$ - power of the combustion engine, $\mathrm{kW}$

$r$-flywheel diameter, $\mathrm{m}$

$R$ - gaseous constant, $\mathrm{J} / \mathrm{kg} \mathrm{K}$

$R e-$ Reynolds number

$\dot{Q}_{\text {all }}$ - total heat transfer through a surface, W

$\dot{Q}_{1}$ - heat flux from the exhaust gas to the wall, W

$\dot{Q}_{2}$ - heat flux from the channel wall to the thermoel. module, W

$\dot{Q}_{\text {ex.n1.3 }}$ - exhaust gas heat flux in $\mathrm{n}^{\text {th }}$ row, for 1 st channel, $\mathrm{W}$

$T_{C}$ - temperature on the cold side of the module, $\mathrm{K}$

$T_{H}$ - temperature on the hot side of the module, $\mathrm{K}$

$T_{1 f}$ - exhaust gas temperature, $\mathrm{K}$

$T_{1 p}$-temperature on the inside of the exhaust gas separator, $\mathrm{K}$

$T_{a m b}$ - ambient temperature, $\mathrm{K}$

$U$ - voltage, $\mathrm{V}$

$w_{e x}$ - exhaust gas velocity in the exhaust gas channel, $\mathrm{m} / \mathrm{s}$

$w_{e d}-$ exhaust gas velocity in the exhaust pipe, $\mathrm{m} / \mathrm{s}$

$W_{d}-$ fuel calorific value, $\mathrm{kJ} / \mathrm{kg}$

$\dot{V}_{\text {air }}$ - volumetric air flow, $\mathrm{m}^{3} / \mathrm{s}$

$V_{\text {air }}$ - actual air volume, $\mathrm{m}^{3} / \mathrm{kg}$

$V_{\text {sk }}$ - swept volume, $\mathrm{dm}^{3}$

$\dot{V}_{e x}$ - volumetric exhaust gas flow, $\mathrm{m}^{3 / \mathrm{s}}$

$Z T$ - non-dimensional quality factor of the thermoelectric module

$\alpha$-Seebeck coefficient, $\mu \mathrm{V} / \mathrm{K}$

$\beta$ - thermoelectric power coefficient, -

$\delta_{t e}$-thickness of the thermoelectric module, $\mathrm{m}$

$\delta_{p}$ - thickness of the channel wall, $\mathrm{m}$ 
$h_{e x}$ - exhaust gas heat transfer coefficient, $\mathrm{W} / \mathrm{m}^{2} \cdot \mathrm{K}$

$\Delta h_{m}$ - local losses, $\mathrm{m}$

$\Delta h_{l}$ - linear losses, $\mathrm{m}$

$\Delta p$ - pressure drop, $\mathrm{Pa}$

$\Delta T_{n}$ - temperature drop between the rows, $\mathrm{K}$

$\varepsilon$ - compression ratio

$\varepsilon_{T}$ - thermoelectric power, $\mathrm{V}$

$\varepsilon_{2 A 1,1 B 2}$ - electromotive power, $\mathrm{V}$

$\eta$-dynamic viscosity, $\mathrm{Pa} \cdot \mathrm{s}$

$\eta_{\text {all }}$ - total efficiency, $\%$

$\eta_{t e}$ - efficiency of the thermoelectric module, \%

$\eta_{\text {TEG }}$ - efficiency of the thermoelectric generator, $\%$

$\kappa$ - adiabatic exponent

$\lambda_{p}$ - heat conductivity coefficient of the gas separator, $\mathrm{W} / \mathrm{m} \cdot \mathrm{K}$

$\lambda_{s l}$ - linear loss coefficient, -

$\lambda_{t e}-$ heat conductivity coefficient of the thermoelement, $\mathrm{W} / \mathrm{m} \cdot \mathrm{K}$

$v$ - specific volume, $\mathrm{m}^{3} / \mathrm{kg}$

$v_{e x}-$ kinematic viscosity of the exhaust gas, $\mathrm{m}^{2} / \mathrm{s}$

$\xi$ - local loss coefficient, -

$\rho_{e x}$ - exhaust gas density, $\mathrm{kg} / \mathrm{m}^{3}$

$\sigma$ - electric conductivity, $\mathrm{S}$

$\tau$ - number of the cylinder

$\omega$ - rotational speed of the flywheel, rad/s

Acknowledgments: This work is sponsored by Ministry of Science and Higher Education in Poland under the grant for Wroclaw University of Science and Technology. Project No 0401/0180/17.

\section{REFERENCES}

1. R. Jakubowski, Jak oszczędzać prąd w samochodzie? [How to save electricity in the car?] http://mojafirma.infor.pl (access 06/17/2017)

2. The thermoelectric generator from $B M W$ is making use of waste heat, BMW AG, MTZ 04/2009 vol.70

3. Koot M., Kessels, J.T.B.A., Energy management for vehicle power nets, de Jager, Bram, van den Bosch, P.P.J. Technische Universiteit Eindhoven, The Netherlands 2004

4. J. G. Kassakian, Automotive electronics power up, IEEE Spectrum, Vol. 37, Issue: 5, 2000

5. C. Sprouse III, C. Depcik, Review of organic Rankine cycles for internal combustion engine exhaust waste heat recovery, Applied Thermal Engineering 51 (2013) 711-722

6. J. S. Jadhao, D. G. Thombare, Review on Exhaust Gas Heat Recovery for I.C. Engine, International Journal of Engineering and Innovative Technology (IJEIT) Volume 2, Issue 12, June 2013

7. H. J. Goldsmid, Introduction to Thermoelectricity, Second Edition, Springer Series in Materials Science,DOI 10.1007/978-3-66249256-7, 2016

8. K.T. Wojciechowski, J. Merkisz, P. Fuc, J. Tomankiewicz, et al., Prototypical thermoelectric generator for waste heat conversion from combustion engines, Combustion Engines No. 3/2013 (154)

9. D. Champier, Thermoelectric generators: a review of applications, Energy Conversion and Management 140 (2017) 167-181

10. J. A. Wajand, J. T. Wajand, Tłokowe silniki spalinowe średnio i szybkoobrotowe [Medium- and high-speed piston engines], Wydawnictwa Naukowo-Techniczne Warszawa, 2000

11. A. Kowalewicz, Podstawy procesów spalania [Basics of combustion processes], Wydawnictwa Naukowo-Techniczne Warszawa 2000
12. M. Gieras, Spalanie - wybrane zagadnienia w zadaniach [Burning - selected issues in tasks], Oficyna Wydawnicza Politechniki Warszawskiej, Warszawa 2011

13. http://www.customthermoelectric.com/powergen.html (access 06/17/2017)

14. P. Fuć, Badania termodynamiczne odzysku odpadowej energii gazów spalinowych z użyciem generatora TEG, raport końcowy projektu nr UMO-2011/01/B/ST8/07241 [Thermodynamic studies of waste gas energy recovery using a TEG generator, final report of the project no UMO-2011/01/B/ST8/07241], 2011-2012.

15. A. F. loffe, Semiconductor Thermoelements and Thermoelectric Cooling, Infosearch, London 1957.

16. K. Glück: Zustands- und Stoffwerte. Wasser. Dampf. Luft. Verbrennungsrechnung. Verlag für Bauwesen GmbH. Berlin, 1991.

17. A. Skoczylas, Przenoszenie ciepła [Heat transfer], Oficyna Wydawnicza Politechniki Wrocławskiej, Wrocław 1991.

18. J. Merkisz, P. Fuć, P. Lijewski, Waste energy recovery analysis of a diesel engine exhaust system, in: Heat Transfer XIII: Simulation and Experiments in Heat and Mass Transfer Simulation and Experiments in Heat and Mass, ed. B. Sundén, C.A. Brebbia, WIT Press, New Forest 2014.

19. K. Jeżowiecka-Kabsch, H. Szewczyk, Mechanika Płynów [Fluid mechanics], Oficyna Wydawnicza Politechniki Wrocławskiej, Wrocław 2001.

\section{Analiza systemu wykorzystującego generator termoelektryczny do odzysku ciepła odpadowego z samochodu}

W pracy przedstawiono algorytm obliczeniowy generatora termoelektrycznego do zastosowania $w$ uktadzie wydechowym silnika samochodowego. W celu sprawdzenia poprawności metody obliczeniowej pokazano jej przydatność na wybranym przykładzie silnika spalinowego. Do obliczeń wykorzystano silnik marki BMW, a konstrukcje generatora oparto o prototyp tej samej marki. Przeprowadzono obliczenia obiegu cieplnego $i$ wyznaczono parametry spalin na wylocie $z$ silnika. Nastepnie wykonano obliczenia przekazywania ciepła od spalin do modutu termoelektrycznego $i$ wyznaczono energie elektryczna uzyskiwana z szeregu modułów. W ostatniej części przedstawiono wpływ prędkości obrotowej silnika na parametry pracy generatora termoelektrycznego.

Authors:

Artur Nemś, PhD - Wroclaw University of Science and Technology, Faculty of Mechanical and Power Engineering, Poland, artur.nems@pwr.edu.pl

Eng. Mikołaj Simiński - Wroclaw University of Science and Technology, Faculty of Mechanical and Power Engineering, Poland

Magdalena Nemś, PhD - Wroclaw University of Science and Technology, Faculty of Mechanical and Power Engineering, Poland

Eng. Tomasz Magiera - Wroclaw University of Science and Technology, Faculty of Mechanical and Power Engineering, Poland

JEL: L62 DOI: 10.24136/atest.2018.144

Data zgłoszenia: 2018.05.23 Data akceptacji: 2018.06.15 